Modern Physics Letters A, Vol. 9, No. 36 (1994) 3413

(C) World Scientific Publishing Company

ERRATA

\title{
GAUGE INDEPENDENCE OF THE FERMION DAMPING RATE IN A HOT PLASMA - LANDAU GAUGE VS COULOMB GAUGE
}

\author{
[Mod. Phys. Lett. A, Vol. 8, No. 8 (1993) 739-748] \\ H. NAKKAGAWA, A. NIÉGAWA and B. PIRE
}

On p. 746 , the second line of Eq. (3.18) should read

$$
\times\left[\frac{q t}{q^{2} t^{2}+\varepsilon^{2}} \operatorname{Im} \Delta_{1}^{(\mathrm{L})}(q t+i \varepsilon, q)-\frac{\varepsilon}{q^{2} t^{2}+\varepsilon^{2}} \operatorname{Re} \Delta_{1}^{(\mathrm{L})}(q t+i \varepsilon, q)\right]
$$

The symbol " $\nu$ " should read " $v$ " in the following places:

(a) p. 744 , (i) Section 3.2 heading.

(ii) Second integral of Eq. (3.11).

(b) p. 745, (i) Second integral of Eq. (3.12).

(ii) Equation (3.13).

(c) p. 746, (i) Section 3.4 heading.

(ii) Second integral of Eq. (3.18).

(iii) Second integral of Eq. (3.19).

(iv) Equation (3.21).

(d) Equation (3.22) on p. 747 . 